Türkiye Jeoloji Bülteni
Geological Bulletin of Turkey
$65(202) 35-42$
doi: $10.25288 /$ tjb.974505

\title{
Permeability Estimation from Stoneley Waves in Carbonate Reservoirs
}

\author{
Keyvan Khayer $^{1} \mathbb{D}$, Adel Shirazy ${ }^{2 *} \mathbb{D}$, Aref Shirazi $^{2} \mathbb{D}$, Abdolhamid Ansari $^{3}$ D \\ Ardeshir Hezarkhani ${ }^{(D)}$
}
${ }^{1}$ Faculty of Mining, Petroleum \& Geophysics Engineering, Shahrood University of Technology, Shahrood, Iran ${ }^{2}$ Faculty of Mining Engineering, Amirkabir University of Technology, Tehran, Iran ${ }^{3}$ Faculty of Mining \& Metallurgical Engineering, Yazd University, Yazd, Iran
- Geliş/Received:26.07.2021 • • Düzeltilmiş Metin Geliş/Revised Manuscript Received: 17.09.2021 • Kabul/Accepted: 20.09 .2021
• Çevrimiçi Yayın/Available online: 14.10.2021 • Bask1/Printed: 20.01.2022

Research Article/Araştırma Makalesi Türkiye Jeol. Bül. / Geol. Bull. Turkey

\begin{abstract}
Permeability is one of the petrophysical properties of oil and gas reservoirs and is defined as the ability of rock to transmit fluids through the porous media. After exploration of any reservoir, permeability information is necessary to optimize the well completion method, oil and gas production and field development. Permeability is determined by both direct and indirect methods. Direct methods are core analysis, well testing, and modular dynamic tester (MDT) and the indirect method is using well logging data such as nuclear magnetic resonance (NMR) and porosity. Determination of permeability from the Stoneley slowness is one of the indirect and continuous methods in the whole well-bore and has been chosen as the goal of this study. The result of this correlation has been plotted against other well logging data and there is a very good match between this result and other petrophysical properties. Due to the complex nature of permeability in carbonate reservoirs, most of the time there is not a good match between this parameter and other petrophysical properties. This study has been conducted on the data of a single well and correlation has been determined. The results show that in calculation of permeability from Stoneley waves, the effective parameters are porosity, lithology, Stoneley slowness and accuracy of the MDT tool. For more precise correlation in a reservoir or a specific geological area, more data from other wells or reservoirs are necessary.
\end{abstract}

Keywords: Carbonate reservoirs, Dipole Shear Sonic imager, permeability, stoneley waves.

\section{INTRODUCTION}

Knowledge of permeability and its distribution is critical in many aspects, such as planning and implementing completion strategies for successful water flooding programs and constructing a representative simulation model for effective reservoir management. Nowadays in industry, core analysis is considered as the most representative permeability tool for micro scale characterization, and well test acquisition is considered as the most representative method to measure permeability for entire reservoir modeling (Burchette, 2012). Core analysis is not possible unless coring a representative sample during or after the drilling operation. In addition, if there is large scale heterogeneity, like in carbonate reservoirs, then a core sample might represent the only local variation. In a carbonate reservoir, high permeability thin streaks might exist, which will be masked by the overall permeability seen through the testing operation. In addition, both coring and testing wells are not performed in every well in a field.

Since $\operatorname{logs}$ are generally performed in every well, several empirical attempts were made to utilize the available $\log$ data to estimate

\footnotetext{
* Correspondence / Yazışma:adel.shirazy@aut.ac.ir
}

(C) 2022 JMO Her hakkı saklıdır/All rights reserved http://tjb.jmo.org.tr http://dergipark.gov.tr/tjb 
permeability. In 1927, Kozeny proposed an equation which related measurable rock properties to permeability that was modified by Carman (Ren et al., 2016). In 1968, based on laboratory studies of 155 sandstone cores from different US oil fields, Timur (1968) proposed a slightly different relationship that was used by the entire oil industry. Neasham (1977) studied the impact of clay on the porosity-permeability relationship in sandstones. In order to measure rock permeability by acoustic logs, the relation between permeability and borehole acoustic waves has been studied both theoretically and experimentally over the past several decades. Rosenbaum (1974) simulated acoustic logs in a porous formation by applying Biot's poroelastic wave theory (Biot, 1962) and found a relationship between permeability and the borehole Stoneley wave (Guan, et al., 2013). This model is therefore termed as the BiotRosenbaum model (Tang \& Cheng, 1996). From acoustic logging data, Williams et al. (1984) also recognized that the velocity and the attenuation of the Stoneley wave are related to formation permeability (Zemanek et al., 1984). Then Tang and Cheng (1996) proposed a fast inversion method to determine formation permeability from Stoneley wave logs (Tang \& Cheng, 1996). Brie et al. (2000) proposed an equation that the Stoneley slowness in a nonpermeable zone can be calculated (Abbott et al., 2000). Al-Adani \& Barati (2003) studied the effect of permeability on Stoneley slowness. They presented Stoneley slowness around the borehole divided into Stoneley slowness in nonpermeable and permeable zones. Hadavandand and Moradzadeh (2007) used Al-Adani's method in sandstone reservoirs and showed that this method is useable in carbonate and sandstone reservoirs (Al-Adani \& Al-Khatib, 2008). Mosalman-Nejad (2008) compared the permeability obtained from Stoneley waves with permeability obtained from NMR (nuclear magnetic resonance) and showed that the result of Stoneley waves has more similarities with core analysis (Jafari et al., 2012). Sun et al. in 2012 studied the full spectrum of sonic waves and examined permeability associated with each type of sonic waves (Sun \& Han, 2012). They found that the variation in speed and the extent of slowness in a Stoneley wave is more related to permeability. Guan et al. (2013) investigated Stoneley waves in water saturated pores and obtained a continuous log that showed the permeability changes around a borehole (Guan et al., 2013; Shirazy et al., 2020 a \& b). Permeability is one of the indicators that can be checked using remote sensing (Shirazi et al., 2018a, b, c, d, \& e). It can also be used to study mineral processing (Doodran et al., 2020; Khakmardan et al., 2020; Shirazy et al., 2020a \&b; Shirazy et al., 2021a \& b).

The aim of this study is to obtain a continuous graph of permeability changes throughout the reservoir formation. For this purpose, using acetone waves and mathematical relations, the permeability value was calculated continuously throughout the formation. The values obtained were also compared with the values measured by the MDT tool.

\section{METHODOLOGY}

The subject of the study is wave-based permeability in carbonate reservoirs. When boreholes are drilled in permeable areas, the movement of liquids in that area increases, which slows down and dampens the wave. In fact, what reflects the wave in the rock is the strong impedance contrasts that appear as Chevron patterns in the variable density log (VDL) display (Ahmed et al., 1991; Brie et al., 2000).

As mentioned above, because the slowness of Stoneley waves is affected by dynamic processes between the borehole and formations, this factor is a qualitative indicator of permeability variation in the whole well-bore. After plotting Stoneley slowness against permeability (MDT 
permeability) data, and calibration of this data with available permeability, this qualitative indicator is converted to a quantitative relationship between permeability and Stoneley slowness (Equation1):

$$
\mathrm{K}=\frac{D T_{\text {st }}-D T_{\text {st none-permeable }}}{\sum_{i=1}^{n} m_{i} v_{i}}
$$

where $\mathrm{DT}_{\mathrm{st}}$ is total Stoneley slowness time, $\mathrm{DT}_{\mathrm{st}}$ non-permeable is Stoneley slowness time in a nonpermeable zone, and $\mathrm{n}$ is the porosity factor necessary to be determined in each reservoir or single well individually. $\mathrm{M}$ is $\sum m_{i} v_{i}$ where is the fraction volume of different lithologies (from petrophysical analysis) and $m_{i}$ is determined by solving a system of two equations that are represented in Equation 2. This equation can determine the accordance factor between Stoneley slowness and the variation of lithology in the formation. (In Equation 2, two types of lithology are assumed, illite and calcite.):

$\left\{\begin{array}{c}V_{i l l} m_{i l l}+V_{c l c} m_{c l c}=M_{\text {oil zone }} \\ V_{i l l} m_{i l l}+V_{c l c} m_{c l c}=M_{\text {water zone }}\end{array}\right.$

where $m_{\text {ill }}$ is the accordance factor between Stoneley slowness and illite, $m_{c l c}$ is the accordance factor between Stoneley slowness and calcite, $V_{\text {ill }}$ is the average volume of illite in each zone, $V_{c l c}$ is the average volume of calcite in each zone, and $M_{\text {oil zone }}$ and $M_{\text {waterzone }}$ are the accordance factors in the oil zone and water zone, respectively.

Stoneley slowness in a non-permeable zone is calculated by using the expression in Equation 3:

$$
D t_{\text {st non-permeable }}^{2}=\frac{\rho_{m}}{\rho_{b}}\left(D t_{s h}\right)^{2}+D t_{b f}^{2}
$$

$D t_{\text {st non-permeable is the slowness in a non- }}$

permeable zone.

$\rho_{b}$ is the bulk density of the rock.

$D t_{b f}$ is the borehole fluid (mud) slowness.

$\rho_{m}$ is the density mud.

$D t_{s h}$ is the shear slowness of the rock.
The difference between $D t_{\text {st non-permeable }}$ and $D t_{s t}$ indicates the fluid mobility indicator. By cross plotting $D t_{\text {st non-permeable versus }}$ $\frac{D t_{s h}}{\rho_{b}}$ across non-permeable zones, the slope of the straight line is and the y-intercept is $D t_{b f}^{2}$. There is one condition in such a linear fit; that all data on the cross plot should be above or on the fit line. According to Equation 4, by determining $D t_{b f}^{2}$, then $D t_{\text {st non-permeable }}$ can be calculated around the borehole:

$\mathrm{Dt}_{\mathrm{st}}=\mathrm{Dt}_{\text {st non-permeable }}+\mathrm{Dt}_{\mathrm{p}}$

\section{DATA}

In this study, the aim is to determine the permeability by Stoneley waves in one of the carbonate reservoirs in the south of Iran. The Fahlian formation is the main reservoir rock of this field, having about 500 meters of carbonate deposits, a gradual boundary over the Garou formation, and a discontinuous boundary under the Gadvan formation. In this study, the Resistivity, SGR, NPHI, Sonic logs and MDT test were acquired. Firstly, the petrophysical analysis was carried out using IP software (Interactive Petrophysics). The petrophysical parameters were determined and are shown in Figure 1. The clay mineral type could not be identified accurately due to the very low concentration of clay in the study zone. Illite was assumed as the main clay mineral in this formation.

\section{RESULTS and DISCUSSION}

First, the calibration factor was determined in each oil and water zone by cross plotting MDT permeability versus $\mathrm{DT}_{\mathrm{st}}$. The slope of the straight line represents the calibration factor. Figures 2 and 3 show these cross plots in the oil and water zone, respectively. 


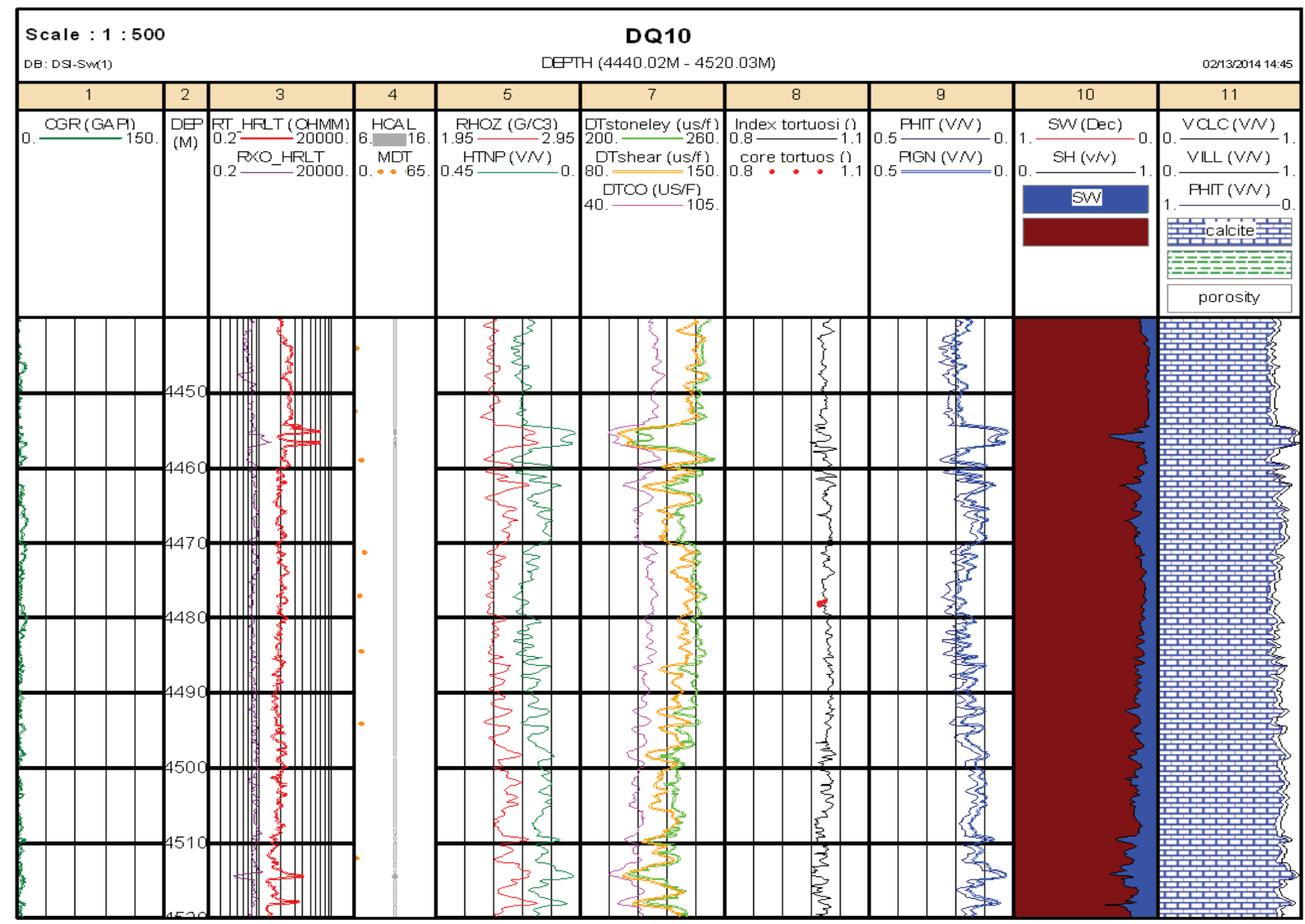

Figure 1. Petrophysical logs in studied well.

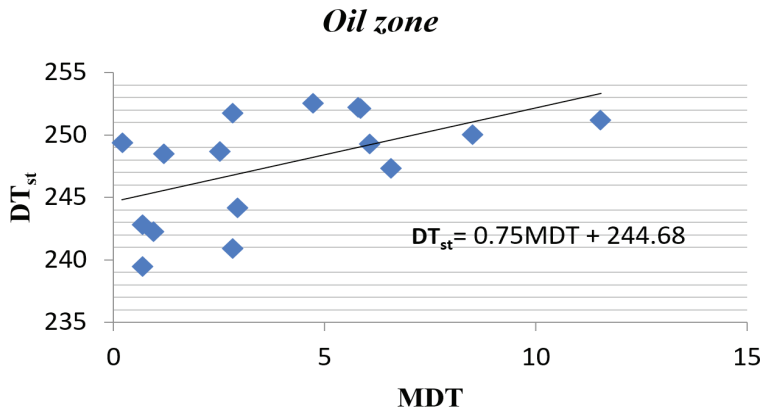

Figure 2. Cross plot of MDT versus $\mathrm{DT}_{\mathrm{st}}$ in oil zone.

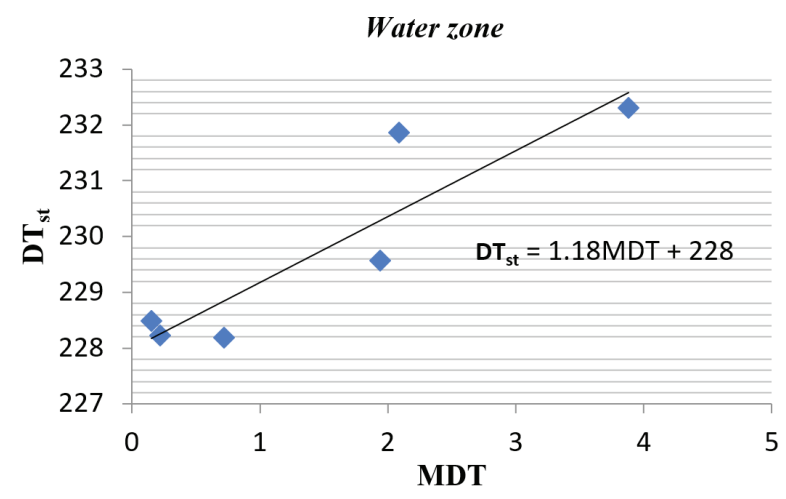

Figure 3. Cross plot of MDT versus $\mathrm{DT}_{\mathrm{st}}$ in water zone. 
As shown in the figures, the calibration factor in the oil zone is equal to 0.75 and in water zone it is equal to 1.18 .

From Equation 2 the $m_{\text {ill }}$ equals 85.213, and $m_{c l c}$ equals 0.347 from Equation 5 .

$$
\left\{\begin{array}{l}
0.00525 m_{\text {ill }}+0.8746 m_{c l c}=0.75 \\
0.01 m_{\text {ill }}+0.9325 m_{\text {clc }}=1.18
\end{array}\right.
$$

Now the Stoneley slowness in non-permeable zone has been calculated by Equation 3 and 4, then by using Equation 1, the continuous quantitative permeability along the bore-hole can be calculated. The generated permeability log with Stoneley slowness measured by the DSI tool is shown in column 9 of Figure 4 . The red point on the log refers to MDT permeability. There is a good fit between the generated log and MDT permeability (Figure 5), equal to $89 \%$.

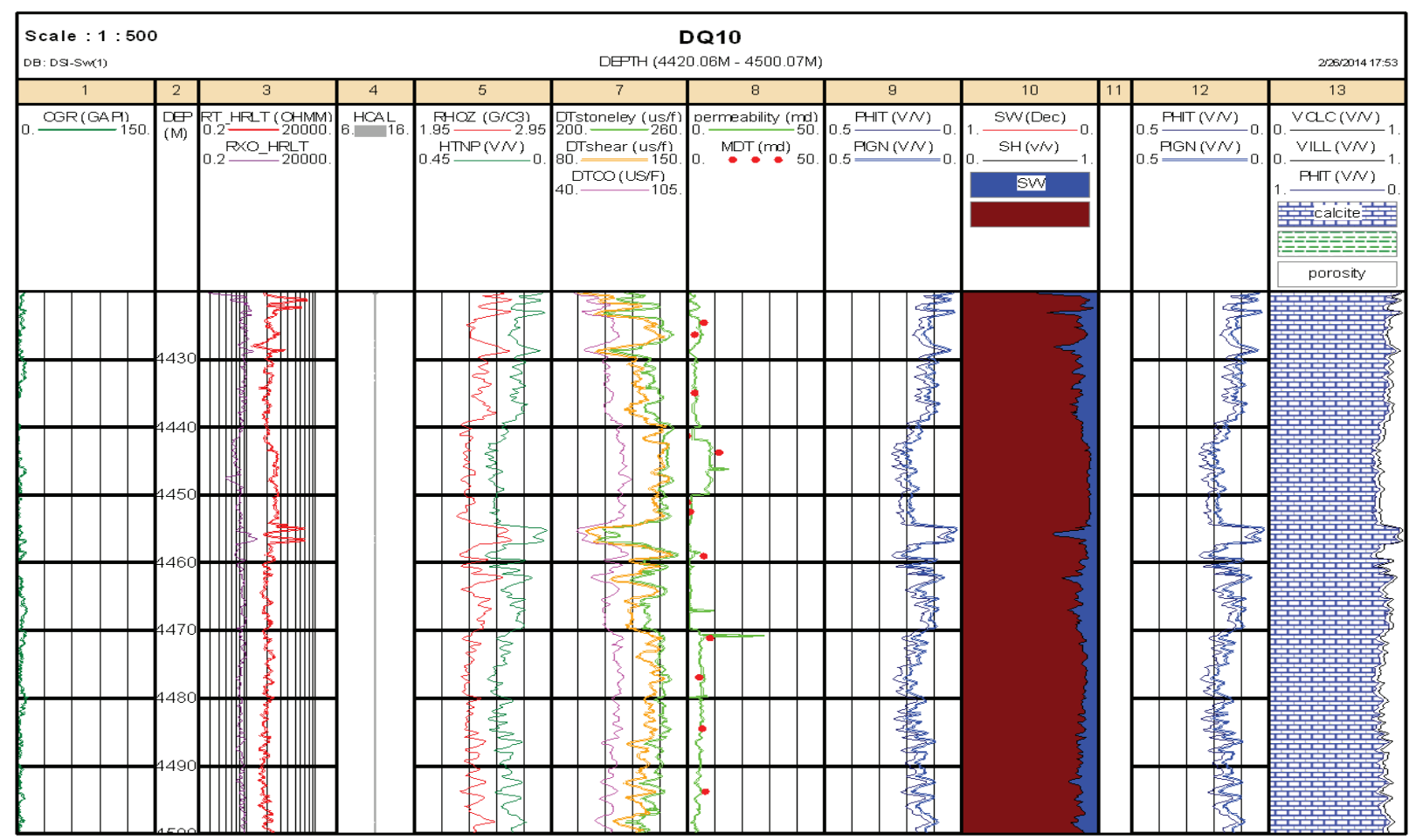

Figure 4. Generated permeability log by Stoneley slowness in column 7. The red points are MDT permeability.

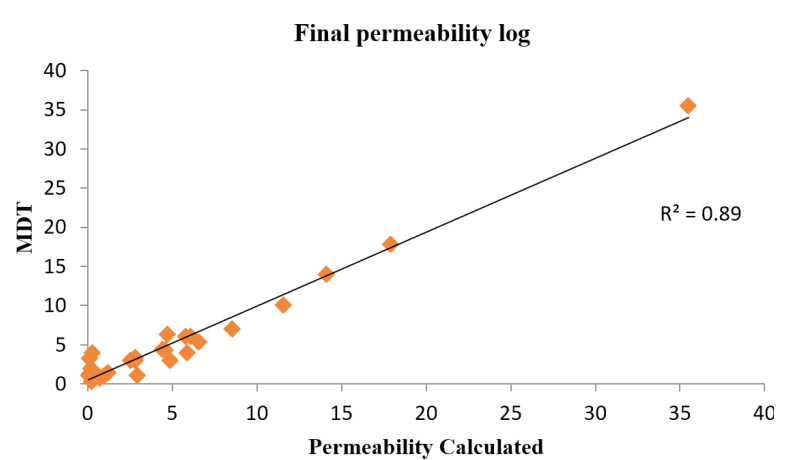

Figure 5. Good match between calculated values and MDT (mD).

\section{CONCLUSION}

The main advantage of using Stoneley waves in estimating permeability is by providing a continuous $\log$ of permeability changes through the borehole without using core data, which are obtained by recording the intrinsic properties of Stoneley waves influenced by permeability and by quantifying the relation between these waves and permeability. In order to calculate an accurate value of permeability by this method, it is 
necessary to consider all parameters which affect permeability.

Results show that one of the effective parameters in this method is the slowness of Stoneley waves in a rock matrix. If the values of this parameter are not accurate enough, the values of the calculated permeability cannot be sufficiently precise. In this study, we used advanced sonic technology to determine permeability in a prolific oil reservoir in one of the carbonate reservoirs in southern Iran. The advanced sonic technology method uses Stoneley wave analysis, in which the input parameters are calibrated with the MDT data. Accordingly, the result of this correlation was plotted against other well logging data and there is a very good match between this result and other petrophysical properties. Due to complex nature of permeability in carbonate reservoirs, there is generally not a good match among the parameters of the cementation coefficient and the porosity and tortuosity coefficients in comparison with other permeability calculation methods, such as artificial neural networks.

This study has been conducted on the data of a single well and a certain correlation has been determined. For more precise correlation in a reservoir or specific geological area, more data is required, such as more wells from which the DSI chart is prepared, or the FMI log.

\section{ORCID}

Keyvan Khayer (D) https://orcid.org/0000-0002-7613-1707

Adel Shirazy (D) https://orcid.org/0000-0001-7756-3205

Aref Shirazi (D https://orcid.org/0000-0001-7623-301X

Abdolhamid Ansari (D https://orcid.org/0000-0003-4777-4065

Ardeshir Hezarkhani (D https://orcid.org/0000-0002-1149-3440

\section{REFERENCES}

Abbott, B., Abolins, M., Abramov, V., Acharya, B., Adams, D., Adams, M. \& Anderson, E. (2000). The bb production cross section and angular correlations in pp collisions at $\mathrm{s}=1.8 \mathrm{TeV}$. Physics Letters B, 487(3-4), 264-272. https://doi. org/10.1016/S0370-2693(00)00844-3

Ahmed, U. ,Crary, S. \& Coates, G. (1991). Permeability estimation: the various sources and their interrelationships. Journal of Petroleum Technology, 43(05), 578-587.

Al-Adani, N. \& Al-Khatib, H. (2008). The Identification of Natural Fractures in Inclined Highly Fractured Formation. 2008 CSPG CSEG CWLS Convention, Calgary, Canada, May 12-15, 2008.

Al-Adani, N. \& Barati, A. (2003). New hydraulic unit permeability approach with DSI. SPWLA 9th Formation Evaluation Symposium of Japan (pp. 25-26).

Biot, M. A. (1962). Mechanics of deformation and acoustic propagation in porous media. Journal of Applied Physics, 33(4), 1482-1498.

Burchette, T. P. (2012). Carbonate rocks and petroleum reservoirs: a geological perspective from the industry. Geological Society, London, Special Publications, 370(1), 17-37:

Brie, A., Endo, T., Johnson, D. \& Pampuri, F. (2000). Quantitative formation permeability evaluation from Stoneley waves. SPE Reservoir Evaluation \& Engineering, 3(02), 109-117.

Doodran, R. J., Khakmardan, S., Shirazi, A. \& Shirazy, A. (2020). Minimalization of Ash from Iranian Gilsonite by Froth Flotation. Journal of Minerals and Materials Characterization and Engineering, 9(1), 1-13.

Guan, W., Hu, H. \& Wang, Z. (2013). Permeability inversion from low-frequency seismoelectric logs in fluid-saturated porous formations. Geophysical Prospecting, 61(1), 120-133.

Hodavand, M. \& Moradzadeh, A., (2007). Estimation of reservoir permeability by studying Stoneley waves [Master's Thesis]. Shahrood University of Technology, Iran

Jafari, S., Mashohor S., Ramli A. R., \& Marhaban M. H. (2012). Expert Pruning Based on Genetic Algorithm in Regression Problems. In: J.S. Pan, S. M.Chen \& Nguyen N.T. (Eds.), Intelligent Information and Database Systems. ACIIDS 2012. Lecture Notes in Computer Science, vol 7198. Springer, Berlin, Heidelberg. 
Khakmardan, S., Doodran, R. J., Shirazy, A., Shirazi, A. \& Mozaffari, E. (2020). Evaluation of Chromite Recovery from Shaking Table Tailings by Magnetic Separation Method. Open Journal of Geology, 10(12), 1153-1163.

Khakmardan, S., Shirazi,A., Shirazy, A. \& Hosseingholi, H. (2018). Copper oxide ore leaching ability and cementation behavior, mesgaran deposit in Iran. Open Journal of Geology, 8(09), 841.

Mosalman-nejad.H, Rezaei. m, Dehghanzadeh. m, (2008), Quantitative permeability evaluation using acoustic waves and comparison with permeability from NMR and core analysis (Kangan Formation in South Pars field). The first congress of Iranian Petroleum Engineering. 106-122

Neasham, J. W. (1977). The morphology of dispersed clay in sandstone reservoirs and its effect on sandstone shaliness, pore space and fluid flow properties. 52nd Annual Fall Technical Conference and Exhibition of the Society of Petroleum Engineers of AIME, Denver, Colorado.

Ren, X., Zhao, Y., Deng, Q., Kang, J., Li, D. \& Wang, D. (2016). A relation of hydraulic conductivityvoid ratio for soils based on Kozeny-Carman equation. Engineering Geology, 213, 89-97.

Rosenbaum, J. H. (1974). Synthetic microseismograms: Logging in porous formations. Geophysics, 39(1), 14-32.

Shirazi, A., Hezarkhani, A.\& Shirazy, A., (2018a). Exploration Geochemistry Data-Application for $\mathrm{Cu}$ Anomaly Separation Based On Classical and Modern Statistical Methods in South Khorasan, Iran. International Journal of Science and Engineering Applications, 7, 39-44.

Shirazi, A., Hezarkhani, A. \& Shirazy, A., (2018b). Remote sensing studies for mapping of iron oxide regions, South of Kerman, Iran. International Journal of Science and Engineering Applications, $7(4), 45-51$.

Shirazi, A., Shirazy, A. \& Karami, J. (2018c). Remote sensing to identify copper alterations and promising regions, Sarbishe, South Khorasan, Iran. International Journal of Geology and Earth Sciences, 4(2), 36-52.

Shirazi, A., Shirazy, A., Saki, S. \& Hezarkhani, A. (2018d). Geostatistics studies and geochemical modeling based on core data, sheytoor iron deposit, Iran. Journal of Geological Resource and Engineering, 6, 124-133.

Shirazy, A., Shirazi, A., Heidarlaki, S. \& Ziaii, M. (2018e). Exploratory Remote Sensing Studies to Determine the Mineralization Zones around the Zarshuran Gold Mine. International Journal of Science and Engineering Applications, 7(9), 274279.

Shirazy, A., Shirazi, A., Ferdossi, M. H. \& Ziaii, M. (2019). Geochemical and geostatistical studies for estimating gold grade in tarq prospect area by k-means clustering method. Open Journal of Geology, 9(6), 306-326.

Shirazy, A., Ziaii, M. \& Hezarkhani, A. (2020a). Geochemical Behavior Investigation Based on K-means and Artificial Neural Network Prediction for Copper, in Kivi region, Ardabil province, IRAN. Iranian Journal of Mining Engineering, 14(45), 96-112.

Shirazy, A., Ziaii, M., Hezarkhani, A. \& Timkin, T. (2020b). Geostatistical and remote sensing studies to identify high metallogenic potential regions in the Kivi area of Iran. Minerals, 10(10), 869.

Shirazy, A., Shirazy, A. \& Nazerian, H. (2021a). Application of Remote Sensing in Earth Sciences-A Review. International Journal of Science and Engineering Applications 10(5), 4551.

Shirazy, A., Shirazi, A., Nazerian, H., \& Khayer, K. (2021b). Geophysical study: Estimation of deposit depth using gravimetric data and Euler method (Jalalabad iron mine, kerman province of IRAN). Open Journal of Geology, 11, 340-355.

Sun, Y. \& Han, J. (2012), Mining heterogeneous information networks: principles and methodologies. Synthesis Lectures on Data Mining and Knowledge Discovery, 3(2), 1-159.

Tang, X. \& Cheng, C.-H. (1996). Fast inversion of formation permeability from Stoneley wave logs using a simplified Biot-Rosenbaum model. Geophysics, 61(3), 639-645.

Timur, A. (1968). An investigation of permeability, porosity, \& residual water saturation relationships for sandstone reservoirs. The Log Analyst, 9, 3-5. 
Williams, J. R., Jones, C. A. \& Dyke, P. T. (1984). A modeling approach to determining the relationship between erosion and soil productivity. Transactions of the ASAE, 27(1), 129-0144.
Zemanek, J., Angona, F., Williams, D. \& Caldwell, R. L. (1984). Continuous acoustic shear wave logging. SPWLA 25th Annual Logging Symposium. 